Journal of Applied Pharmaceutical Science Vol. 5 (10), pp. 142-146, October, 2015

Available online at http://www.japsonline.com

DOI: $10.7324 / \mathrm{JAPS} .2015 .501024$

ISSN 2231-3354 (cc) BY-NC-SA

\title{
The effect of different grades polymer blends on release profiles of diclofenac sodium from hydrophilic matrices
}

\author{
Sachin S. Mitkare ${ }^{1 *}$, Dinesh M. Sakarkar ${ }^{2}$ \\ ${ }^{1}$ Department of Pharmaceutics, School of Pharmacy, SRTM University, Nanded-431606, M.S. India. \\ ${ }^{2}$ Department of Pharmaceutics, S.N. Institute of Pharmacy, Pusad-445204, M.S. India.
}

\begin{tabular}{|c|c|}
\hline ARTICLE INFO & ABSTRACT \\
\hline Article history: & \multirow{10}{*}{$\begin{array}{l}\text { An attempt was made to design matrix tablet of diclofenac sodium by using various grades of hydroxypropyl } \\
\text { methyl cellulose (HPMC E50, E15 and E300LV). The effect of hydrophilic polymers was studied on release } \\
\text { characteristics of the diclofenac matrix tablet. Dicalcium phosphate and magnesium stearate were used as an } \\
\text { excipients. Tablets were prepared by direct compression method. The in vitro dissolution test carried out for } 12 \\
\text { hrs using USP dissolution apparatus II at } 50 \mathrm{rpm} \text { in } 900 \mathrm{ml} \text { phosphate buffer pH } 6.8 \text {. Statistically significant } \\
\text { difference was found among the drug release profile from different matrices. The tablet evaluation parameters } \\
\text { of hardness, friability, thickness, content uniformity were founded within the limit. At a fixed polymer level, } \\
\text { drug release from the higher viscosity grades E50 was slower as compared to the lower viscosity grades } \\
\text { (E300LV and E15). Tablet prepared with HPMC E50 is more release retardant. As the drug to polymer ratio } \\
\text { increased drug release decreased. The dissolution study revealed that maximum retardation of the drug was } \\
\text { obtained by highest viscosity grade HPMC at higher concentrations. The release of the model drug from these } \\
\text { HPMC matrix tablets was prolonged. }\end{array}$} \\
\hline //07/2015 & \\
\hline Revis & \\
\hline Accepted on: $30 / 08 / 2015$ & \\
\hline Available online: $28 / 10 / 2015$ & \\
\hline & \\
\hline Diclofenac sodium, & \\
\hline Hydrophilic matrix, & \\
\hline Hydroxypropylmethylcellulose, & \\
\hline & \\
\hline
\end{tabular}

\section{INTRODUCTION}

Diclofenac sodium is a non-steroidal anti-inflammatory agent, which is commonly used for rheumatoid arthritis as longterm therapy. The biological half-life of diclofenac sodium is about 1-2 hrs; therefore to maintain a therapeutic drug blood level, it requires multiple dose. After long-term and frequent administration of diclofenac sodium, it gives adverse side effects like gastrointestinal disturbances, peptic ulceration, and perforation (Scholer et al., 1986; Lin et al., 1991). Diclofenac sodium is one of the most useful NSAIDs agents. It is a practically insoluble in an acidic solution (pKa 4.0), but get dissolved in intestinal fluid and water (Bravo et al., 2004). The conventional tablets make the drug immediately available for absorption in the upper GI tract resulting local GI toxicity varying from minorgastric discomfort to ulceration and bleeding of the mucosa (Carson et al., 1990 and Sivakumar et al., 2010). It is well documented that the GI toxicity is not only caused by the inhibition of the prostaglandin synthesis, but it is probably also

\footnotetext{
* Corresponding Author

E-mail: sachinpharma08@gmail.com
}

due to direct contact of the drug with the mucosa (Carson et al., 1990). In addition, due to the rapid systemic clearance of this drug, repeated daily dosing of 3 to 4 times a day is required in maintenance therapy that influences patient compliance. Sustained release formulations of diclofenac sodium are thus supposed to promote patient compliance and to reduce upper GI toxicity to some extent. Diclofenac sodium is well absorbed in the colon (Bjamason et al., 1991) and thus colon-specific release of this drug can be used for the treatment of widespread inflammatory bowel diseases. The matrix tablet by direct compression can be formulated with technological simplicity. As compared to other controlled release systems, matrix tablets required fewer unit operations, less equipments, reduced number of personnel and processing time, enhanced product stability and production rate. Hydroxypropylmethylcellulose is a swellable and hydrophilic polymer, widely used in solid dosage form. Some research groups have worked on the usage of swellable HPMC as the retarding polymer to sustain the release of different drugs (Gleiter et al., 1985). It is very suitable to use HPMC as release retardant material in matrix tablets (Heng et al., 2001 and Lee et al., 1999). 


\section{MATERIALS AND METHODS}

Diclofenac sodium was received as a gift sample from the Wockhardt research center, Aurangabad. Hydroxypropylmethylcellulose E50, E15, E300LV purchased from Merck Pvt. Limited, Mumbai. All the other excipients and chemicals were of analytical grade and procured from S D Fine Chemical, Mumbai.

\section{Method of tablet preparation at different ratio}

All the material containing diclofenac sodium, filler (ditab), lubricant (magnesium stearate), and flow promoter (aerosil) passed through sieve \# 60, triturated and mixed in mortar and pestle. This mixture was then compressed in the 12 station compression machine (Karnavati, India), by using $9 \mathrm{~mm}$ punch. The all formulations batches and their codes mentioned in table1.

\section{Evaluation of powder characteristics SR matrix tablets (IP,} 1996; Liberman and Lachman , 1991)

\section{Bulk density}

Bulk density was determined by placing the drug excipients blend into a graduated cylinder and measuring the volume and weight by using the following formula.

$$
\text { Bulk density }=\frac{\text { Weight of the powder }}{\text { Bulk Volume of the powder }}
$$

\section{Tapped density}

Tapped density was determined by USP method II tablet blend was filled with $100 \mathrm{ml}$ graduated cylinder of tap density tester which was operated for a fixed number of taps until the powder bed volume has reached a minimum, thus was calculated by the following formula.

$$
\mathrm{D}_{\mathrm{t}}=\frac{M}{V_{b}}
$$

Where, $\mathrm{D}_{\mathrm{t}}=$ Tapped density; $\mathrm{M}=$ Weight of powder taken; $\mathrm{V}_{\mathrm{b}}=$ Tapped volume.

\section{Angle of repose}

Tablet blend was poured from funnel, to form the heap of powder. Height (h) \& diameter (D) of powder were measured. The repose angle $\theta$ was calculated by the following formula.

$$
\operatorname{Tan} \theta=\frac{h}{r}
$$

Where, $\theta=$ angle of repose; $h=$ height of the cone; $r=$ radius of the cone

\section{Carr's index}

It is an indirect method of measuring powder flow from bulk densities was developed by Carr. The compressibility of the granulations was determined by the following formula (Tetsuo et al., 2005).

$$
\text { Carr's index }(\%)=\frac{\text { Tapped } \text { density }- \text { Bulk density }}{\text { Tapped density }} \times 100
$$

Evaluation of tablet (I.P., 1990; Liberman and Lachman, 1991; Tetsuo et al., 2005)

\section{Weight variation}

Twenty tablets were randomly selected from each batch individually weigh, the average weight and standard deviation of 20 tablets was calculated.

\section{Thickness}

Thickness and diameter of tablets were determined by using calibrated Vernier caliper. 20 tablets from each batch were selected randomly, and their average thickness was measured.

\section{Hardness}

The Hardness was measured by using the Pfizer hardness tester, for each batch three tablets were tested.

\section{Friability}

For each formulation, the friability of 20 tablets was determined using the Roche friabilator (Lab Hosp). This test subjects a number of tablets to the combined effect of shock, abrasion by utilizing a plastic chamber which revolves at a speed of $25 \mathrm{rpm}$, dropping the tablets to a distance of 6 inches in each revolution. A sample of reweighed 20 tablets was placed in Roche friabilator, which was then operated for 100 revolutions for 4 minutes. The tablets were then dusted and reweighed.

\section{Drug content uniformity}

Five tablets were weighed individually, and these tablets were crushed in a mortar. Drug equivalent to $10 \mathrm{mg}$ of powder was taken, to this $10 \mathrm{ml}$ of distilled water was added. The absorbance was measured at $276 \mathrm{~nm}$ after suitable dilution using double beam UV visible spectrophotometer. The drug content was determined.

In vitro drug dissolution studies (Ming-Thau et al., 1992 and Samanta et al., 2010)

In vitro drug release study for the prepared matrix tablets was conducted for a period of $12 \mathrm{hrs}$ using a six-station USP type II (paddle) apparatus at $37^{\circ} \mathrm{C}$ and $50 \mathrm{rpm}$ speed. The dissolution studies were carried out for $12 \mathrm{hrs}$ in the distilled water. $0.1 \mathrm{~N} \mathrm{HCl}$ and phosphate buffer $\mathrm{pH}$ 6.8, Sampling were done after every $1 \mathrm{hr}$ interval; samples of $10 \mathrm{ml}$ were withdrawn from dissolution medium and replaced with fresh medium to maintain the volume constant. The release rates from these hydrophilic polymeric matrices were conducted in a medium of by changing the $\mathrm{pH}$ by starting with a tablet in $\mathrm{HCl}$ solution ( $\mathrm{pH} \mathrm{1.2)} \mathrm{for} 2 \mathrm{hrs}$. Then, the tablets were immersed in a phosphate buffer $(\mathrm{pH} \mathrm{6.8)}$ for $8 \mathrm{hrs}$. The sample solutions were analyzed for diclofenac sodium by UVabsorbance at $276 \mathrm{~nm}$ using a spectrophotometer. The cumulative percentage of drug release was calculated.

\section{RESULTS AND DISCUSSION}

\section{Drug polymer interaction study}

Compatibility of excipients with diclofenac sodium was studied by Fourier Transform Infrared Spectroscopy (Shimadzu). 
The FT-IR spectra of all the combinations containing drug and polymer shows same or slightly shift in peak values which revealed that all polymers used are compatible with drug, as shown in fig. 1.

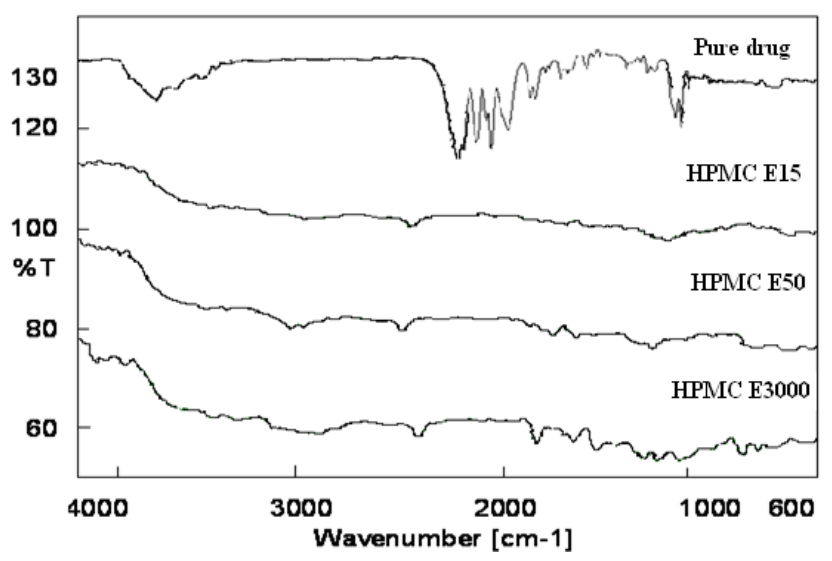

Fig. 1: FT- IR Spectra of API and excipients.

\section{Evaluation of powder characteristic of SR tablets}

The powders prepared for compression of tablets were evaluated for their flow properties. The powder characteristic indicates good flowability with an angle of repose value ranging from 25-30 i.e. (<30). The angle of repose of all formulations was found to be the range of $23.10 \pm 0.750$ to $28.38 \pm 0.12$. The bulk density of all the formulations showed acceptable range. The bulk density of these powders was found to be in the range of $0.424 \pm$ 0.06 to $0.630 \pm 0.02 \mathrm{gm} / \mathrm{cm}^{3}$ for all formulations. The measured tapped density was in the range of $0.440 \pm 0.06$ to $0.870 \pm$ $0.05 \mathrm{gm} / \mathrm{cm}^{3}$ for all formulations. Carr's index of powder was found the range of $09.00 \pm 0.02$ to $20.00 \pm 0.02$ for all formulations. These values indicate that the prepared powder exhibited good flow properties. The result mentioned in the table 2 .

\section{Characterization of SR tablets}

The weights of the tablets of all formulations found with low standard deviation values, representing uniformity of weight. The difference in weight was within the range of $5 \%$ complying with Pharmacopeial specification (Indian Pharmacopoeia). The weight variation deviation of different formulations was found to be between 3.102 to 4.584 . The hardness for different formulations was found to be between $4.8 \pm 0.22$ to $6.6 \pm 0.16 \mathrm{~kg} / \mathrm{cm}^{2}$. It was indicated satisfactory mechanical strength. The diameter and thickness of all the formulations were found in the range of $9.10 \pm$ 0.03 to $9.18 \pm 0.05 \mathrm{~mm}$ and $3.23 \pm 0.04$ to $3.43 \pm 0.02 \mathrm{~mm}$ respectively. The friability of all formulations was found to be between $0.46 \pm 0.04$ to $0.65 \pm 0.06 \%$. The tablets compressed were stable and having better physical characteristics. The percentage drug content for different tablet formulation varied from $95.32 \pm$ 0.03 to $99.32 \pm 0.03$ was found to be within limits which indicate uniform drug distribution in all formulations, the limit $(85 \%$ to $115 \%$ ) of $\%$ drug content allowed by I.P., the result of tablet characterization is mentioned in the table 3 .

\section{In vitro drug dissolution studies of diclofenac sodium}

In the formulation $\mathrm{T}_{1}(1: 1), \mathrm{T}_{2}(1: 2)$ and $\mathrm{T}_{3}(1: 3)$ shows drug release $102.16 \%, 85.77 \%$ and $81.33 \%$ respectively in $12 \mathrm{hrs}$, shown in Fig.2. As the concentration of polymer increased drug release decreased. $\mathrm{T}_{4}(1: 1)$ released $101.24 \%$ drug in $7 \mathrm{hrs} . \mathrm{T}_{5}$ (1:2), $\mathrm{T}_{6}(1: 3)$ gives drug release $86.69 \%, 80.51 \%$ respectively at the end of 12 hrs, shown in Fig.3. Whereas in the formulation of $\mathrm{T}_{7}$ it shows $105.16 \%$ drug release in only $6 \mathrm{hrs}$ at lower concentration, i.e. $(1: 1)$, while $\mathrm{T}_{8}(1: 2), \mathrm{T}_{9}(1: 3)$ gives drug release $100.28 \%$, 93.04\% respectively at the end of $12 \mathrm{hrs,} \mathrm{shown} \mathrm{in}$ Fig.4. Results of cumulative percentage drug release are shown in table 4. Comparative graph of drug release through all the formulations is shown in Fig.5.

Table 1: Composition of matrix tablet of diclofenac sodium (250mg).

\begin{tabular}{|c|c|c|c|c|c|c|c|c|c|}
\hline Ingredients & $\mathbf{T}_{1}$ & $\mathbf{T}_{2}$ & $\mathbf{T}_{3}$ & $\mathbf{T}_{4}$ & $\mathbf{T}_{5}$ & $T_{6}$ & $\mathbf{T}_{7}$ & $\mathbf{T}_{8}$ & $\mathbf{T}_{9}$ \\
\hline Diclofenac sodium & 50 & 50 & 50 & 50 & 50 & 50 & 50 & 50 & 50 \\
\hline HPMC E50 & 50 & 100 & 150 & - & - & - & - & - & - \\
\hline HPMC E15 & - & - & - & 50 & 100 & 150 & - & - & - \\
\hline HPMC E300LV & - & - & - & - & - & - & 50 & 100 & 150 \\
\hline Dicalcium phosphate (Ditab) & 147 & 97 & 47 & 147 & 97 & 47 & 147 & 97 & 47 \\
\hline Magnesium stearate & 2 & 2 & 2 & 2 & 2 & 2 & 2 & 2 & 2 \\
\hline Aerosil & 1 & 1 & 1 & 1 & 1 & 1 & 1 & 1 & 1 \\
\hline Drug: Polymer (ratio) & 1:1 & $1: 2$ & $1: 3$ & 1:1 & $1: 2$ & $1: 3$ & 1:1 & $1: 2$ & $1: 3$ \\
\hline
\end{tabular}

(All ingredients are taken in $\mathrm{mg}$ per tablet)

Table 2: Comparative study of powdered characteristics for formulation

\begin{tabular}{|c|c|c|c|c|}
\hline Batch Code & Angle of repose $(\theta)$ & Bulk Density $\left(\mathrm{g} / \mathrm{cm}^{3}\right)$ & Tapped Density $\left(\mathrm{g} / \mathrm{cm}^{3}\right)$ & Carr'sIndex (IC) \\
\hline $\mathrm{T}_{1}$ & $25.71 \pm 0.21$ & $0.568 \pm 0.02$ & $0.870 \pm 0.05$ & $16.00 \pm 0.02$ \\
\hline $\mathrm{T}_{2}$ & $27.57 \pm 0.08$ & $0.621 \pm 0.04$ & $0.725 \pm 0.07$ & $09.00 \pm 0.02$ \\
\hline $\mathrm{T}_{3}$ & $28.38 \pm 0.12$ & $0.530 \pm 0.02$ & $0.561 \pm 0.03$ & $17.32 \pm 0.03$ \\
\hline $\mathrm{T}_{4}$ & $24.04 \pm 0.340$ & $0.468 \pm 0.02$ & $0.641 \pm 0.02$ & $13.60 \pm 0.12$ \\
\hline $\mathrm{T}_{5}$ & $23.10 \pm 0.750$ & $0.521 \pm 0.04$ & $0.561 \pm 0.03$ & $14.00 \pm 0.02$ \\
\hline $\mathrm{T}_{6}$ & $27.99 \pm 0.57$ & $0.630 \pm 0.02$ & $0.461 \pm 0.03$ & $20.00 \pm 0.02$ \\
\hline $\mathrm{T}_{7}$ & $24.04 \pm 0.340$ & $0.432 \pm 0.02$ & $0.661 \pm 0.02$ & $19.00 \pm 0.02$ \\
\hline $\mathrm{T}_{8}$ & $28.10 \pm 0.750$ & $0.424 \pm 0.06$ & $0.440 \pm 0.06$ & $14.00 \pm 0.14$ \\
\hline $\mathrm{T}_{9}$ & $25.99 \pm 0.47$ & $0.588 \pm 0.03$ & $0.490 \pm 0.01$ & $12.18 \pm 0.02$ \\
\hline Broad Range & $23.10 \pm 0.750$ to $28.38 \pm 0.12$ & $0.424 \pm 0.06$ to $0.630 \pm 0.02$ & $0.440 \pm 0.06$ to $0.870 \pm 0.05$ & $09.00 \pm 0.02$ to $20.00 \pm 0.02$ \\
\hline
\end{tabular}

Mean \pm SD $(n=3)$. 
Table 3: Physico-chemical characterization of diclofenac sodium tablets.

\begin{tabular}{|c|c|c|c|c|c|c|c|}
\hline \multirow{2}{*}{$\begin{array}{l}\text { Batch } \\
\text { Code }\end{array}$} & \multicolumn{2}{|c|}{ Weight variation } & \multirow{2}{*}{$\begin{array}{c}\text { Hardness } \\
\left(\mathrm{kg} / \mathrm{cm}^{2}\right)\end{array}$} & \multirow{2}{*}{$\begin{array}{c}\text { Diameter } \\
(\mathbf{m m})\end{array}$} & \multirow{2}{*}{$\begin{array}{c}\text { Thickness } \\
\text { (mm) }\end{array}$} & \multirow{2}{*}{$\begin{array}{c}\text { Friability } \\
(\%)\end{array}$} & \multirow[t]{2}{*}{ Assay (\%) } \\
\hline & Average Weight (mg) & Highest (\%) deviation & & & & & \\
\hline $\mathrm{T}_{1}$ & 249 & 4.215 & $6.3 \pm 0.35$ & $9.18 \pm 0.05$ & $3.33 \pm 0.01$ & $0.54 \pm 0.02$ & $97.02 \pm 0.02$ \\
\hline $\mathrm{T}_{2}$ & 251 & 3.816 & $5.6 \pm 0.12$ & $9.11 \pm 0.03$ & $3.34 \pm 0.09$ & $0.63 \pm 0.05$ & $98.42 \pm 0.03$ \\
\hline $\mathrm{T}_{3}$ & 250 & 4.105 & $5.2 \pm 0.16$ & $9.13 \pm 0.08$ & $3.43 \pm 0.02$ & $0.56 \pm 0.04$ & $99.13 \pm 0.05$ \\
\hline $\mathrm{T}_{4}$ & 251 & 3.543 & $5.5 \pm 0.26$ & $9.14 \pm 0.04$ & $3.23 \pm 0.04$ & $0.53 \pm 0.03$ & $99.32 \pm 0.03$ \\
\hline $\mathrm{T}_{5}$ & 250 & 4.520 & $6.6 \pm 0.16$ & $9.17 \pm 0.02$ & $3.30 \pm 0.01$ & $0.65 \pm 0.06$ & $97.32 \pm 0.04$ \\
\hline $\mathrm{T}_{6}$ & 248 & 4.584 & $4.9 \pm 0.26$ & $9.12 \pm 0.03$ & $3.37 \pm 0.09$ & $0.55 \pm 0.02$ & $96.51 \pm 0.04$ \\
\hline $\mathrm{T}_{7}$ & 253 & 3.102 & $6.2 \pm 0.16$ & $9.15 \pm 0.04$ & $3.36 \pm 0.01$ & $0.57 \pm 0.02$ & $95.32 \pm 0.03$ \\
\hline $\mathrm{T}_{8}$ & 249 & 3.942 & $5.9 \pm 0.26$ & $9.14 \pm 0.02$ & $3.29 \pm 0.03$ & $0.60 \pm 0.05$ & $98.32 \pm 0.04$ \\
\hline $\mathrm{T}_{9}$ & 251 & 3.586 & $4.8 \pm 0.22$ & $9.10 \pm 0.03$ & $3.40 \pm 0.05$ & $0.46 \pm 0.04$ & $97.51 \pm 0.04$ \\
\hline
\end{tabular}

Mean \pm SD (n=3).

Table 4: Dissolution profile of DCF- HPMC E50, HPMC E15 and HPMC E300LV.

\begin{tabular}{|c|c|c|c|c|c|c|c|c|c|}
\hline \multirow{2}{*}{$\begin{array}{l}\text { Time } \\
\text { (hrs) }\end{array}$} & \multicolumn{9}{|c|}{ \% Cumulative release } \\
\hline & $\mathbf{T}_{1}$ & $\mathbf{T}_{2}$ & $\mathbf{T}_{3}$ & $\mathbf{T}_{4}$ & $\mathbf{T}_{5}$ & $\mathbf{T}_{6}$ & $\mathbf{T}_{7}$ & $\mathbf{T}_{8}$ & $\mathbf{T}_{9}$ \\
\hline 0 & 00 & 00 & 00 & 00 & 00 & 00 & 00 & 00 & 00 \\
\hline 1 & 23.68 & 19.67 & 16.43 & 40.21 & 22.59 & 23.31 & 47.49 & 22.59 & 20.46 \\
\hline 2 & 32.38 & 23.67 & 20.43 & 51.83 & 33.09 & 32.37 & 55.88 & 27.68 & 24.65 \\
\hline 3 & 40.38 & 32.73 & 27.68 & 59.87 & 40.73 & 43.61 & 68.61 & 32.43 & 35.66 \\
\hline 4 & 51.64 & 43.61 & 40.71 & 72.61 & 51.63 & 48.75 & 82.10 & 38.62 & 40.42 \\
\hline 5 & 58.96 & 48.76 & 45.48 & 80.70 & 56.06 & 55.35 & 89.12 & 45.20 & 46.63 \\
\hline 6 & 63.77 & 55.35 & 49.90 & 89.16 & 60.15 & 58.71 & 105.16 & 52.86 & 50.70 \\
\hline 7 & 69.31 & 57.64 & 55.06 & 101.24 & 66.05 & 60.28 & & 60.19 & 56.93 \\
\hline 8 & 74.87 & 60.65 & 57.71 & & 72.33 & 66.18 & & 68.24 & 64.99 \\
\hline 9 & 80.87 & 68.35 & 61.02 & & 75.72 & 68.49 & & 73.08 & 73.06 \\
\hline 10 & 88.42 & 73.54 & 65.53 & & 80.21 & 72.60 & & 84.41 & 81.14 \\
\hline 11 & 96.55 & 81.27 & 73.24 & & 82.91 & 76.72 & & 92.88 & 87.09 \\
\hline 12 & 102.16 & 85.77 & 81.33 & & 86.69 & 80.51 & & 100.28 & 93.04 \\
\hline
\end{tabular}

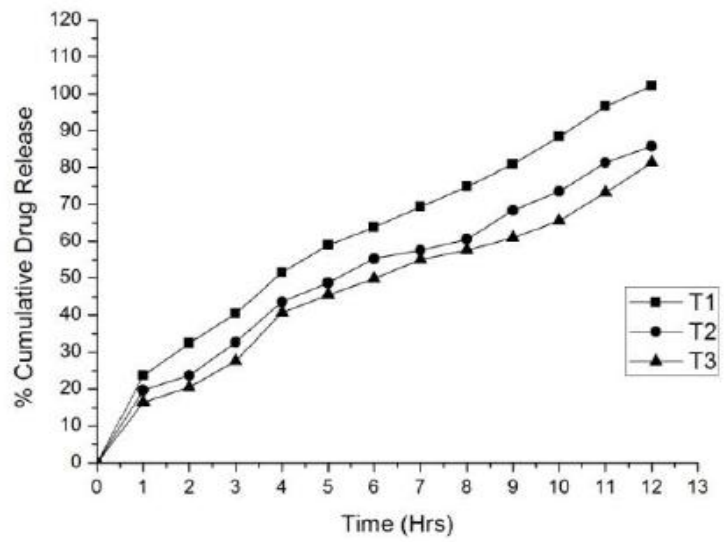

Fig. 2: Comparative dissolution study of DCF- HPMC E50.

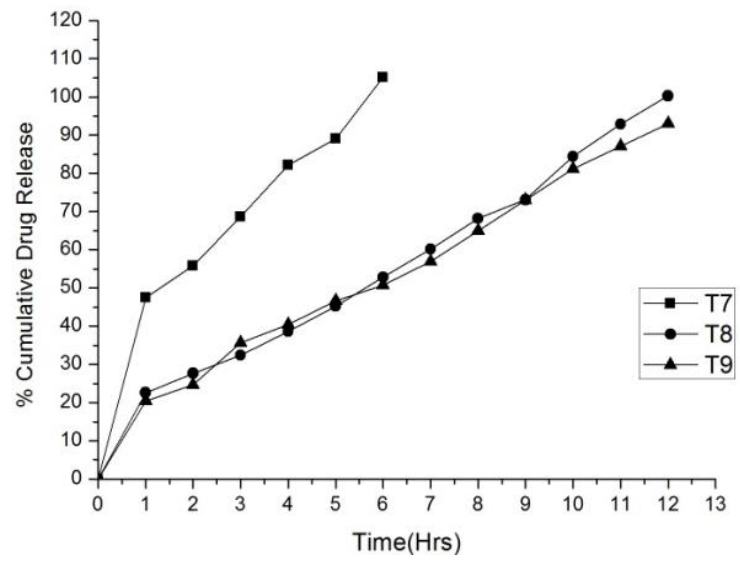

Fig. 4: Comparative dissolution study of DCF- HPMC E300LV.

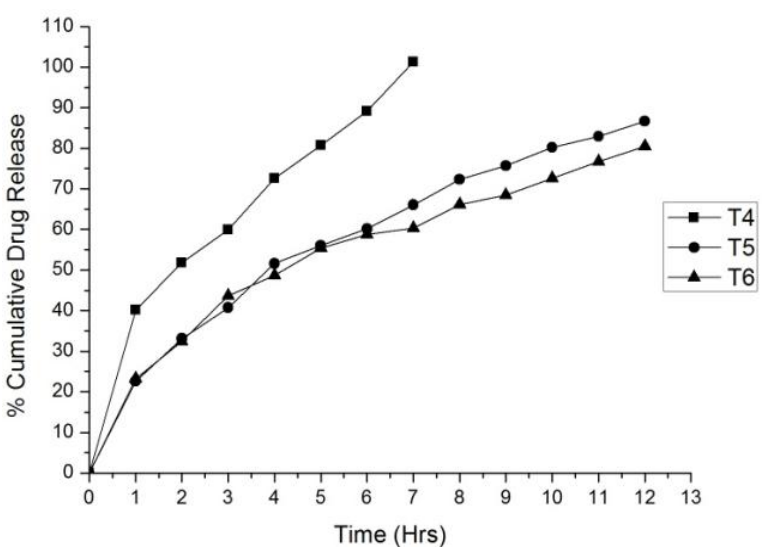

Fig. : 3 Comparative dissolution study of DCF- HPMC E15.

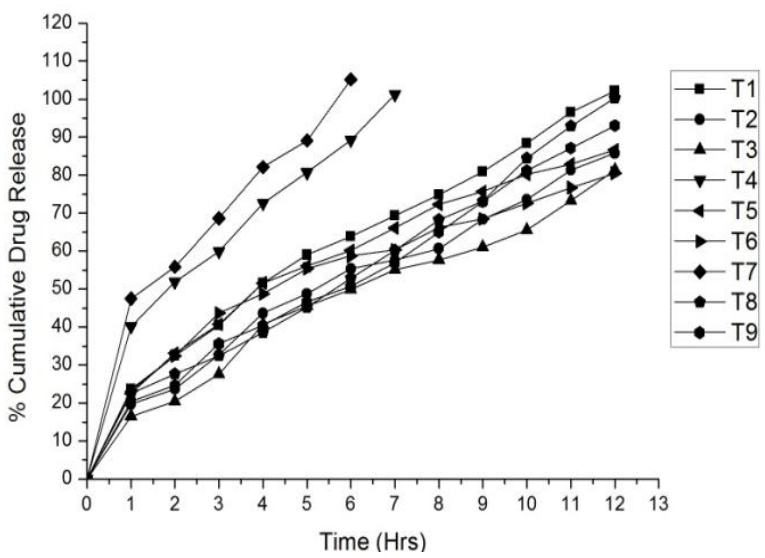

Fig. 5 : Comparative dissolution study of all formulation. 
At fixed drug to polymer ratio it was found that a formulation containing HPMC E50 is more release retardant than HPMC E15 and HPMC 300LV. Formulation $\mathrm{T}_{3}$ (containing E50 $1: 3$ ) retarded drug release more, while formulation $\mathrm{T}_{7}$ (containing HPMC E300LV 1:1) was less release retardant. HPMC E50 was significantly more successful at retarding drug release than HPMC E15 and HPMC E300LV; it might be due to its high viscosity. Drug release retard found in order $T_{3}>T_{2}>T_{1}>T_{6}>T_{5}>T_{4}>T_{9}>T_{8}$ $>\mathrm{T}_{7}$. Among all polymers used HPMC E50 retards drug release more than HPMC E15 and HPMC E300LV. Drug release retard was found in order HPMC E50 > HPMC E15 > HPMC E300LV.

\section{CONCLUSION}

From the preformulation and precompression studies, it was concluded that diclofenac sodium suitable drug candidate for the formulation of hydrophilic matrix tablets and the formulated tablets showed compliance for various physiochemical parameters. According to the in vitro drug release studies, the decrease in the release rate was observed with an increase in the viscosity of the polymer. As the drug to polymer ratio increased, more drug gets retarded from tablets. The tablet formed with HPMC E50 controlled drug release more than HPMC E15 and HPMC E300LV. The order of drug release retardation was HPMC E50>HPMC E15>HPMC E300LV.

\section{ACKNOWLEDGEMENT}

Author is thankful to Director, School of Pharmacy, Department of Pharmaceutics, Swami Ramanand Teerth Marathwada University, Nanded for providing facilities to carry out the present research work.

\section{REFERENCES}

Bjarnason I, Fehilly B, Smethurst P, Menzies I S, Levi A J., Importance of local versus systemic effects of non-steroidal antiinflammatory drugs in increasing small intestinal permeability in man. Gut, 1991, 32, 275-277.

Bravo SA, Lamas MC, Salomon CJ., Swellable matrices for the controlled-release of diclofenac sodium: formulation and in vitro studies. Pharm Dev Technol., 2004, 9(1), 75-83.
Carson J, Notis WM, Orris ES., Colonic ulceration and bleeding during Diclofenac therapy N Engl J Med,1990, 323(2),135-137.

Gleiter $\mathrm{CH}$, Antonin $\mathrm{KH}$, Bieck P, Godbillon J, Schönleber W, Malchow H., Colonoscopy in the investigation of drug absorption in healthy volunteers. Gastrointest Endosc., 1985, 31 (2), 71-73.

Heng PWS, Chan LW, Easterbrook MG, Li X., Investigation of the influence of mean HPMC particle size and number of polymer particles on the release of aspirin from swellable hydrophilic matrix tablets. J Control Release. 2001, 76, 39-49.

Lee BJ, Ryu SG, Cui JH., Formulation and release characteristics of hydroxypropylmethylcellulose matrix tablets containing melatonin. Drug Dev Ind Pharm., 1999, 25 (4); 493-501.

Liberman H, Lachman L, Joseph B., Text book of Pharmaceutical dosage forms; Tablets, Revised \& expanded, Volume I, Second edition, 1991, 2-52.

Lin SY, Kao YH., Tablet formulation study of spray-dried sodium diclofenac enteric-coated microcapsules. Pharm Res., 1991, 8, 919-924.

Ming-Thau Sheu, Huei-Lan Chou, Ching-Cheng Kao, ChengHsiung Liu, Theodore D. Sokoloski, Dissolution of diclofenac sodium from matrix tablets. International Journal of Pharmaceutics, 1992, 85 (13); 57-63.

Samanta C. Mourao, Cristiane da Silva, Tania M.B. Bresolin, Cristina H.R. Serra, Valentina Porta, Dissolution parameters for sodium diclofenac-containing hypromellose matrix tablet. International Journal of Pharmaceutics, 2010, 386, 1-2: 201-207.

Scholer DW, Ku EC, Boettacher I, Schweizer., A Pharmacology of diclofenac sodium. Am J Med., 1986, 80, (4B), 34-38.

Sivakumar T, Vipul Kumar Shingala, Anoop Kumar Singh, Sudhir Kumar Yadav., Design and characterization of diclofenac sodium tablets containing Mangifera indica resin as release retardant. Int J Pharm Tech Research, 2010, 2, 2107-2111.

Tetsuo Hayashi, Hideyoshi Kanbe, Minoru Okada, Makoto Suzuki, Yasuo Ikeda, Yoichi Onuki, Tetsuo Kaneko, Takashi Sonobe., Formulation study and drug release mechanism of a new theophylline sustained-release preparation. International Journal of Pharmaceutics, 2005, 304 (1-2); 91-101.

The Indian Pharmacopoeia. The Controller of Publication, Govt. of India, Delhi, Edition IV, Vol. 2, 1996, A82-A85

\section{How to cite this article:}

Mitkare SS and Sakarkar DM. The effect of different grades polymer blends on release profiles of diclofenac sodium from hydrophilic matrices. J App Pharm Sci, 2015; 5 (10): 142-146. 